\title{
Bicuspid aortic valve-associated aortopathy: A slowly evolving picture
}

\author{
Christian D. Etz, MD, PhD, and Michael A. Borger, MD, PhD
}

From the Department of Cardiac Surgery, Heart Center Leipzig, Leipzig, Germany.

Disclosures: Authors have nothing to disclose with regard to commercial support.

Received for publication Oct 12, 2017; accepted for publication Oct 13, 2017; available ahead of print Nov 29, 2017.

Address for reprints: Michael A. Borger, MD, PhD, Department of Cardiac Surgery, Heart Center Leipzig, Leipzig, Germany (E-mail: michael.borger@helios-kliniken.de).

J Thorac Cardiovasc Surg 2018;155:472-3

$0022-5223 / \$ 36.00$

Copyright (c) 2017 by The American Association for Thoracic Surgery

https://doi.org/10.1016/j.jtcvs.2017.10.041

The bicuspid aortic valve (BAV) — until a few decades ago considered a rather harmless anomaly affecting up to $2 \%$ of the general population-has been progressively recognized as a heterogeneous entity associated with a variety of severe aortic wall pathologies. The relationship between BAV and associated aortopathy is complex and has been the focus of numerous articles. In the current issue of the Journal, Wojnarski and colleagues ${ }^{1}$ have shed more light on this topic by using machine-learning classification of computed tomography scans in patients with BAV undergoing thoracic aortic surgery. The authors identified 3 phenotypes of BAV aortopathy (ie, root, ascending, and arch) that are associated with various morphologic and clinical characteristics.

Several studies have focused on BAV phenotypes and morphology to gain insights into the cause of BAV aortopathy and to better define the risk of future aortic complications. Advanced imaging technologies, in particular 4-dimensional magnetic resonance imaging, have been used to support the hypothesis that altered blood flow architecture through the BAV triggers structural aortic wall pathology by increasing local wall stress in certain subgroups of patients. Studies focusing on functional BAV status and morphology have revealed several important findings, including the following.

1. Patients with BAV experience acute aortic dissection at a younger age and a larger diameter than their tricuspid peers. ${ }^{2}$ In addition, patients with BAV with dissection present more frequently with aortic insufficiency and an entry tear in the aortic root. ${ }^{2}$ This observation supports earlier and more aggressive intervention for the patient with "root phenotype" BAV.

2. BAV functional phenotype (ie, BAV stenosis vs aortic insufficiency) correlates significantly with the expression and severity of bicuspid aortopathy. Mild-tomoderate ascending aortic dilatation remains stable after aortic valve replacement in patients with BAV aortic stenosis. $^{3,4}$ In contrast, patients with aortic root dilatation and a regurgitant valve (ie, root phenotype) are at

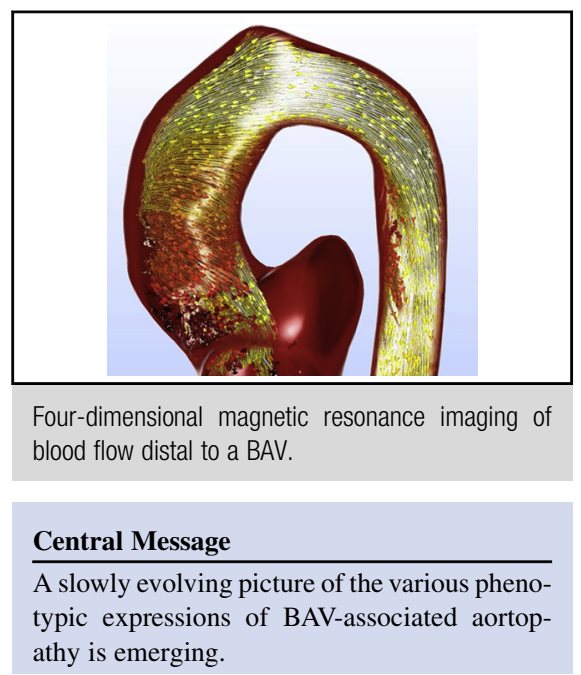

See Article page 461

significant risk for aortic events after isolated aortic valve replacement. ${ }^{3,4}$

3. Aortic root replacement in young patients with BAV, particularly those with root phenotype, may cure BAV-associated aortic disease and achieve excellent long-term outcomes.

Wojnarski and colleagues, ${ }^{1}$ in the largest published cohort to date of patients with BAV with associated aortopathy, support these findings and further elucidate the heterogeneity of BAV aneurysm formation. They identified 3 distinct phenotype clusters of aortic dilation in patients with predominately dysfunctional aortic valves. The results supply more evidence supporting close follow-up of young male patients with regurgitant BAVs, who are more likely to have a genetic component that triggers structural aortic wall weakness. These patients are prone to develop proximal aortic root phenotypes at a young age and are likely to benefit from a more aggressive surgical strategy.

Whether individual phenotype-based risk stratification in patients with normal aortic valvular function is of prognostic value requires further evaluation and cannot be answered by the current report. In addition, further studies are required to determine whether the identified phenotypes are associated with distinct structural wall alterations. Such a finding would add further evidence to the theory that different etiologic mechanisms are involved in the various BAV phenotypes. The story of 
BAV-associated aortopathy is complex, but the picture is gradually becoming more clear.

\section{References}

1. Wojnarski CM, Roselli EE, Idrees JJ, Zhu Y, Carnes TA, Lowry AM, et al. Machine learning phenotypic classification of bicuspid aortopathy. J Thorac Cardiovasc Surg. 2018;155:461-9.

2. Etz CD, von Aspern K, Hoyer A, Girrbach FF, Leontyev S, Bakhtiary F, et al. Acute type A aortic dissection: characteristics and outcomes comparing patients with bicuspid versus tricuspid aortic valve. Eur J Cardiothorac Surg. 2015;48:142-50.
3. Girdauskas E, Rouman M, Disha K, Fey B, Dubslaff G, von Kodolitsch Y, et al. Morphologic and functional markers of aortopathy in patients with bicuspid aortic valve insufficiency versus stenosis. Ann Thorac Surg. 2017; 103:49-57.

4. Girdauskas E, Rouman M, Disha K, Dubslaff G, Fey B, Misfeld M, et al. The fate of mild-to-moderate proximal aortic dilatation after isolated aortic valve replacement for bicuspid aortic valve stenosis: a magnetic resonance imaging follow-up $\dagger$. Eur J Cardiothorac Surg. 2016;49:e80-6.

5. Etz CD, Homann TM, Silovitz D, Spielvogel D, Bodian CA, Luehr M, et al. Longterm survival after the Bentall procedure in 206 patients with bicuspid aortic valve. Ann Thorac Surg. 2007;84:1186-93. 